\title{
Comparison of the effects of Lactobacillus plantarum versus imipenem on infected burn wound healing
}

\author{
Somayeh Soleymanzadeh Moghadam ${ }^{1}$, Nazanin Mohammad ${ }^{1}$, Maryam Ghooshchian ${ }^{1}$, Sara FathiZadeh ${ }^{1}$, \\ Zohreh Khodaii ${ }^{2}$, Mahmood Faramarzi ${ }^{3}$, Zeinab Fagheei Aghmiyuni ${ }^{1}$, Masoud Roudbari ${ }^{1,4}$, Abdolreza Pazouki ${ }^{5}$, \\ Tahereh Mousavi Shabestari*1 (1D
}

Received: 19 Jan 2019

Published: 8 Aug 2020

Abstract

Background: Infection of burn wounds is one of the most important problems in the world. Lactobacillus plantarum is known for burn wound healing because of the immunomodulatory and anti-microbial roles. This study was performed to compare the effects of $L$. plantarum and imipenem - alone and in combination - on infected burn wound healing.

Methods: Burn wounds were experimentally induced on 50 rats in three test groups (germ and supernatant of L. plantarum) and two control groups $(\mathrm{n}=10$ each) and were inoculated with Pseudomonas aeruginosa. During a 14-day period, wounds in all groups were daily treated topically. The data were analyzed using one-way analysis of variance followed by Tukey-Kramer and LSD. A p-value of $<0.05$ was considered as statistically significant.

Results: The mean size of the wound on day 14 after the treatment in the probiotic group was significantly lower than the control and the supernatant treated groups $(\mathrm{p}<0.05)$. The percentage of wound healing was significantly higher in the probiotic pellet treated group compared to the imipenem and the supernatant groups (by Anova test: 69.58\%, $\mathrm{p}=0.022$ ). The mean leukocyte count in the probiotic pellet group (12110) and supernatant group (13650) was significantly higher than the imipenem group (7670) ( $\mathrm{p}=0.002$ and 0.001 , respectively). Wound cultures revealed that the percentage of cases where the pathogens had no growth was significantly different among the comparison groups. In all three test groups, $P$. aeruginosa was completely eliminated in comparison to the positive control group $(\mathrm{p}<0.05)$.

Conclusion: The results of our study showed that L. plantarum and its by-products promote wound healing and can be used as an alternative to antibiotics to treat ulcer infections caused by resistant bacteria.

Keywords: Lactobacillus plantarum, Imipenem, Burn, Wound healing

Conflicts of Interest: None declared

Funding: This work was supported by Iran University of Medical Sciences with grant number 1393.24557.

\section{*This work has been published under CC BY-NC-SA 1.0 license. \\ Copyright $\odot$ Iran University of Medical Sciences}

Cite this article as: Soleymanzadeh Moghadam S, Mohammad N, Ghooshchian M, FathiZadeh S, Khodaii Z, Faramarzi M, Fagheei Aghmiyuni Z, Roudbari M, Pazouki A, Mousavi Shabestari T. Comparison of the effects of Lactobacillus plantarum versus imipenem on infected burn wound healing. Med J Islam Repub Iran. 2020 (8 Aug);34:94. https://doi.org/10.47176/mjiri.34.94

\section{Introduction}

Burns are a major cause of many psychological, physical, and economic injuries (1-4). The frequency and rates of antibiotic resistance among pathogenic bacterial populations can be attributed to the widespread use of

Corresponding author: Dr Tahereh Mousavi Shabestari, mousavi.ta@iums.ac.ir

Antimicrobial Resistance Research Center, Institute of Immunology and Infectious Diseases, Iran University of Medical Sciences, Tehran, Iran

2. Dietary Supplements and Probiotic Research Center, Alborz University of Medical Science, Karaj, Iran

3. Research Center of Pediatric Infectious Diseases, Institute of immunology and infectious diseases, Iran University of medical sciences, Tehran, Iran

4. Department of Biostatistics, School of Public Health, Iran University of Medical Sciences, Tehran, Iran

5. Division of Minimally Invasive Surgery Fellowship Program, Rasoul Akram Hospital, Iran University of Medical Science, Tehran, Iran antibiotics leading to nosocomial and community-acquired infections (5-7).

Although burn wound surfaces are sterile at the time of a thermal injury, these wounds finally become colonized

$\uparrow$ What is "already known" in this topic:

Some Lactobacillus strains and their products have significant inhibitory activities against multidrug resistant clinical isolates.

\section{$\rightarrow$ What this article adds:}

This study showed that $L$. plantarum and its by-products promote wound healing and can be used as an alternative to antibiotics to treat ulcer infections caused by resistant $P$. aeruginosa. 
with microorganisms such as Staphylococcus aureus, Pseudomonas aeruginosa, fungal pathogens particularly Candida spp. and Herpes simplex virus (8). P. aeruginosa, as a major opportunistic human pathogen, carries antimicrobial resistance properties that make it difficult to treat infected burn wounds and is considered as the main cause of death in burned patients (8-11) Therefore, it is essential to find new ways to control drug-resistant $P$. aeruginosa infections.

Previous studies have shown that the intestinal microflora ceases the growth and adherence of pathogenic bacteria to enterocytes. $(12,13)$ The World Health Organization (WHO) has promoted the use of gastrointestinal microflora, termed probiotics, aiming at achieving health benefits in the host $(14,15)$.

Lactobacillus plantarum 299v (L. plantarum 299v), a Gram-positive facultative anaerobic or microaerophilic bacterium, which was first isolated from the human intestine, uses mannose-specific adhesions that help it to compete with Gram-negative and positive bacteria for receptor sites and nutrients in the mucosal membrane (1618). In addition, they secrete antibacterial substances such as lactic acid, benzoic acid, hydrogen peroxide, and bacteriocins $(19,20)$ that contribute to the inhibition of forming pathogenic bacterial colonies (21). Moreover, production of short-chain fatty acids (SCFAs) by $L$. plantarum 299v lowers the intestinal $\mathrm{pH}$, creating an unfavorable environment for the growth of pathogens (21, 22). This strain has been reported to have antibacterial activity against several potential pathogenic microorganisms including $P$. aeruginosa, Listeria monocytogenes, Escherischia coli and Enterococcus faecalis (23-25). Some Lactobacillus strains and their products have significant inhibitory activities against multidrug-resistant clinical isolates of $P$. aeruginos $a$ and are also effective in the local treatment of burn infections $(25,26)$. L. plantarum $299 v$ is able to survive in severe environments, even in the presence of antibiotics (26-28). These properties make this strain a superior probiotic compared to other commensal bacterial strains.

The main goal of this research was to compare the effects of L. plantarum in the form of bacterial cell pellet, supernatant and combination of both, as well as the use of imipenem, as therapeutic strategies for infected burn wounds of rats.

\section{Methods}

Clinical isolates: Thirty clinical samples of burn wounds were collected from patients of hospitalized in Motahari Hospital, Tehran, Iran. The samples were transferred to the microbiology unit of Antimicrobial Resistance Research Center to investigate the presence of $P$. aeruginosa using conventional microbiological methods (29).

Antimicrobial Susceptibility Testing: Antibiotic sensitivity patterns of $P$. aeruginosa isolates were investigated by disk diffusion(dd) method using Mueller Hinton agar medium based on the recommendations of the Clinical and Laboratory Standards Institute (CLSI, 2017). Antibacterial susceptibility of $P$. aeruginosa strains was evaluated for eight different antibiotic disks (Mast Group Ltd., Merseyside, UK). Antibiotic disks included Ceftazidime $(30 \mu \mathrm{g})$, Ciprofloxacin $(30 \mu \mathrm{g})$, Gentamicin $(10 \mu \mathrm{g})$, Amikacin $(30 \mu \mathrm{g})$, Imipenem $(10 \mu \mathrm{g})$, Cefipime $(30 \mu \mathrm{g})$ and Tetracycline $(30 \mu \mathrm{g})$. P. aeruginosa ATCC 27853 was used for quality control in the study. Results were interpreted as susceptible, intermediate, or resistant according to the standards. The antibiotic-resistant strains were selected for the in-vivo step in this study.

In this research, the bacteria were cultured on MuellerHinton agar with $0.5 \mathrm{McF}$ arland standards. Then the discs placed on the medium and were incubated at $37^{\circ} \mathrm{C}$ for 16 hours.

Preparation, cultivation, and selection of probiotic bacteria: In this study, different strains of probiotics were obtained from the Probiotic Research Center of Alborz University of Medical Sciences, Karaj, Iran and DSM. (26). The commercial probiotic strains used in this study were Bacillus coagulans (DSM1), Bifidobacterium bifidum (DSM20456) and L. plantarum 299v (DSM9843). The local Lactobacillus strains included L. salivarius strain ES1, L. reuteri strain ES10 and L. salivarius strain ES8. The Lactobacillus strains were grown anaerobically on De Man, Rogosa and Sharpe (MRS broth at $37^{\circ} \mathrm{C}$ for $48 \mathrm{~h}$ (30). After that, they were transferred to the MRS agar medium. Then, they were standardized based on 0.5 McFarland standards $\left(1.5 \times 10^{8} \mathrm{cfu} / \mathrm{ml}\right)$ and were kept at $4^{\circ} \mathrm{C}$.

Antimicrobial activity of probiotic strains against pathogens: The inhibitory activity of the probiotic strains against $P$. aeruginosa was evaluated using the disk diffusion method as described by NCCLS (31). The selected resistant $P$. aeruginosa was examined using probiotic coated disks. For this purpose, a blank disk (6 $\mathrm{mm}$ in diameter) was inoculated with $20 \mu \mathrm{l}$ probiotic suspension $\left(1.5 \times 10^{8} \mathrm{cfu} / \mathrm{ml}\right.$ bacteria $)$ and was placed on a nutrient agar medium and was incubated at $37^{\circ} \mathrm{C}$ for $16 \mathrm{~h}$. Afterward, the probiotic strain with the longest inhibitory diameter was selected for the next step (Fig. 1 and Fig. 2).

Preparation of probiotic supernatant: In this section, the supernatant was prepared by centrifuging of probiotic suspension at $4000 \mathrm{rpm}$ for 10 minutes. The centrifuged suspension was filtered through a sterile $0.22 \mu$-pore-size filter unit. Finally, the cell-free supernatant (CFS) and precipitated cells of probiotics were collected and kept at $4^{\circ} \mathrm{C}$ until use $(32,33)$.

Animals: This experimental study was carried out in the Animal Laboratory of Iran University of Medical Sciences with ethic committee code IR.IUMS.REC1393.24557. Fifty male adult Wistar rats of similar age (8-10 weeks) and weight (200-250 gr) were maintained under controlled conditions of light (12h light/dark photoperiod), room temperature $\left(32 \pm 2^{\circ} \mathrm{C}\right)$ and relative humidity $(60-70 \%)$. They were kept in polyethylene boxes with enough appropriate space and free access to food and water that were refreshed every day.

Induction of wounds and treatment procedure: The animals were anesthetized using $100 \mathrm{mg} / \mathrm{kg}$ of ketamine and $10 \mathrm{mg} / \mathrm{kg}$ of xylazine (34) injected to intraperitoneal space, then the hair on the dorsal areas was 
S. Soleymanzadeh Moghadam, et al.

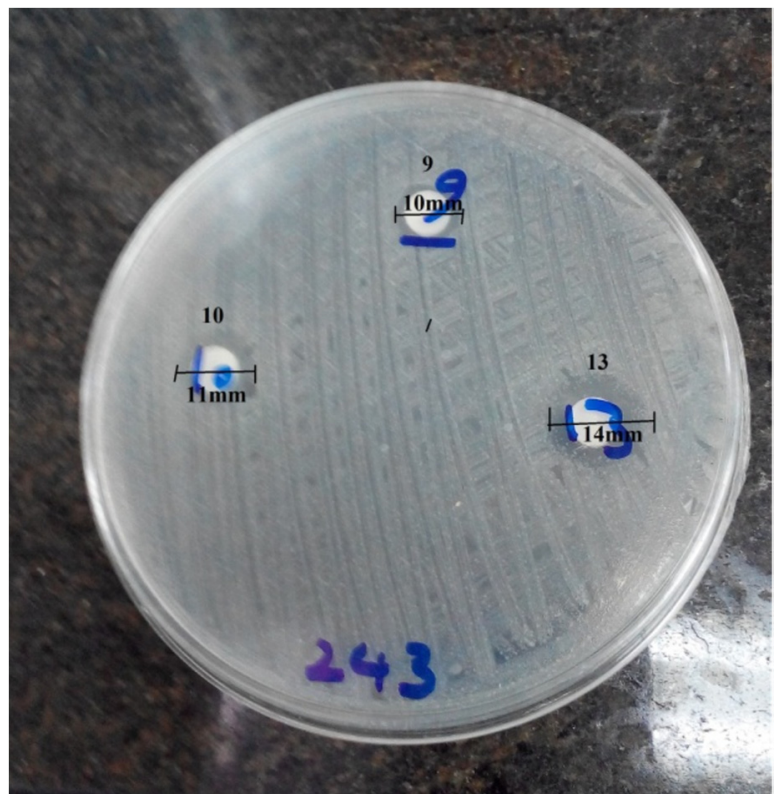

Fig. 1. Inhibition zone of $P$. aeroginosa caused by Lactobacillus spp by disk diffusion method. Disk 8: L. Plantarum299v (16mm), disk 9: L. salivarius ES1 (0mm), Disk 10: Bacillus Coagulans (0mm), disk 11: L. reuteri ES10 (0mm), disk 12: L. salivarius ES7 (0mm), disk 13: Bifidobacterium bifidum (0mm).

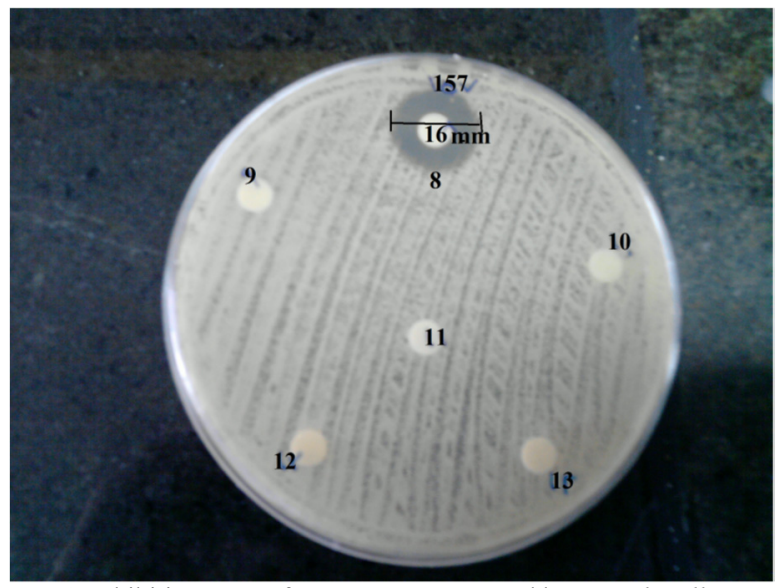

Fig. 2. Inhibition zone of $P$. aeroginosa caused by Lactobacillus spp by disk diffusion method. Disk 9: L. salivarius ES1 (10mm), Disk 10: Bacillus Coagulans (11mm), disk 13: Bifidobacterium bifidum (14mm).

shaved, disinfected with ethanol $70 \%$ and were then exposed to a hot steel rod with a temperature of $95^{\circ} \mathrm{C}$ and a diameter of $2 \mathrm{~cm}$. Thereafter, the wounds were covered with sterile gauze. Twenty-four hours later, the wounds were inoculated with $1 \mathrm{ml}$ of $P$. aeruginosa $\left(1.5 \times 10^{8}\right.$ $\mathrm{CFU} / \mathrm{ml})$. All rats were divided into 5 groups $(\mathrm{n}=10$ each) $24 \mathrm{~h}$ after the induction of infection randomly. Burn wounds in all groups were topically treated with a eucerin ointment containing different compositions daily for 14 days. The treatment applied on each group are described as: $0.9 \% \mathrm{NaCl}$ (negative control group), imipenem (positive control group), the cells of probiotics (test group 1), supernatant of probiotics (test group 2) and combination of germ and supernatant of probiotic (test group 3) (Table 1).

Table 1 shows the different formulations used in each
Table 1. Animals in different groups treated with different formulations

\begin{tabular}{lc}
\hline Groups $(\mathrm{n}=10)$ & Interventions \\
\hline Negative control & $\begin{array}{c}\text { Eucerin ointment }+0.9 \% \mathrm{NaCl}(1 \mathrm{~g} / 1 \mathrm{ml}): \\
\text { Without treatment }\end{array}$ \\
Positive control & $\begin{array}{c}\text { Eucerin ointment }+ \text { imipenem }(1 \mathrm{~g} / 1 \mathrm{mg}) ; \\
\text { imipenem }(50 \mathrm{mg} / 1 \mathrm{~kg})\end{array}$ \\
Test 1 & $\begin{array}{c}\text { Eucerin ointment }+ \text { probiotic cell pellet } \\
\left(1 \mathrm{~g} / 10^{8}\right)\end{array}$ \\
Test 2 & $(\mathrm{~g} / 1 \mathrm{ml})$ \\
Test 3 & Eucerin ointment + supernatant of probiotic \\
& Eucerin ointment $+($ probiotic cell pellet + \\
& supernatant of probiotic) $\left(10^{8} / 1 \mathrm{~g} / \mathrm{ml}\right)$ \\
\hline
\end{tabular}

group of rats. Ten rats in each group were studied (total population $=50$ ).

Evaluation of the wound healing process: All animals were sacrificed by the use of high doses of ether anesthetics on the 14th day of the treatment and evaluations were conducted as follows:

Morphological assessment of the wounds: Burn wounds were evaluated $24 \mathrm{~h}$ after induction of burn (before initiation of treatment: day 0 ), on the $7^{\text {th }}$ and $14^{\text {th }}$ day of treatment by measuring the area of the wounds with the naked eye with a ruler (35). The percentage of wound recovery was computed according to the following formula (1).

wound area on first day $\left(\mathrm{mm}^{2}\right)-$ wound area on last day $\left(\mathrm{mm}^{2}\right)$ $\times 100$

Burn wound hematological assessment: Blood samples were collected by heparin-coated tubes. Leukocytes were counted on days 0,7 , and 14 using a cell counter device (Cell Counter Refreshed Sysmex kx2).

Burn wound bacterial infection assessment: On days 0 , 7 , and 14 , the surface layers of the lesions were removed by a wet sterile swab in all animals and were cultured on blood agar medium and then were incubated at $37^{\circ} \mathrm{C}$. The cultures were assessed for $p$. aeruginosa after $24 \mathrm{~h}$ using common laboratory tests (35).

Statistical analysis: The data was analyzed by SPSS software, version 20.0. Comparison between the groups were done using one-way analysis of variance (ANOVA) followed by Tukey-Kramer and LSD (post Hoc tests). A $\mathrm{p}$-value $<0.05$ was considered as statistically significant.

\section{Results}

Antibiotic Susceptibility Testing: The resistance patterns of 30 strains of $P$. aeruginosa to some of the antibiotics were investigated. The frequency of the resistance of $P$. aeruginosa isolates against the tested antibiotics (number/percentage) are as follows: Ceftazidime (30/100), Gentamicin (28/93.4), Amikacin (28/93.4), Imipenem (30/100), Cefipime (30/100), Ciprofloxacin $(30 / 100)$ and Tetracycline $(88 / 60)$. All of the tested strains showed resistance to ceftazidime, imipenem, cefepime and ciprofloxacin. These results reflect the low susceptibility of tested strains to other tested antibiotics. Of 30 samples, the one with the highest antimicrobial resistance was selected for animal assay. The resistance was examined based on the diameter of the inhibition

Med J Islam Repub Iran. 2020 (8 Aug); 34.94. 
Table 2. Antimicrobial activity of some bacterial probiotics against resistant $P$. aeruginosa

\begin{tabular}{lc}
\hline Bacteria & Mean of inhibitory zone (mm) \\
\hline Bacillus Coagulans (DSM1) & 10 \\
Bifidobacterium bifidum & 14 \\
L. Plantarum299v (DSM9843) & 16 \\
L. salivarius ES1 & 10 \\
L. reuteriES10 & 10 \\
L. salivariusES7 & 0 \\
\hline
\end{tabular}

zone.

In-vitro effects of probiotic bacteria on P. aeruginosa: The antibacterial activity of Bacillus coagulans (DSMI), Bifidobacterium bifidum and L. plantarum $299 \mathrm{v}$ (DSM9843) as commercial probiotic strains, and also local Lactobacillus strains including L. salivarius ES1, L. reuteri ES10, L. salivarius ES7 was tested against resistant $P$. aeruginosa (Table 2).
The antimicrobial activity of probiotic strains was studied based on the inhibition zones (total population of $P$. aeroginosa $=30$ ). The mean of the inhibitory zones was measured for every P. aeroginosa strain (Table 2).

The results showed that L. Plantarum299v had the highest inhibitory diameter $(16 \mathrm{~mm})$ against selected resistant $P$. aeruginosa compared to other probiotics (Fig. 1 and Fig. 2).

Evaluation of wound healing process in rats: After the treatment procedure, the wound healing process in all animals was investigated and the following factors were taken into consideration on the 14th day of treatment:

Survey of morphology of wound: Wound sizes were measured twenty-four hours after the induction of burn and also on the $7^{\text {th }}$ and $14^{\text {th }}$ days of the treatment with the naked eye (Fig. 3 and Fig. 4).

A description of groups is presented here. Negative

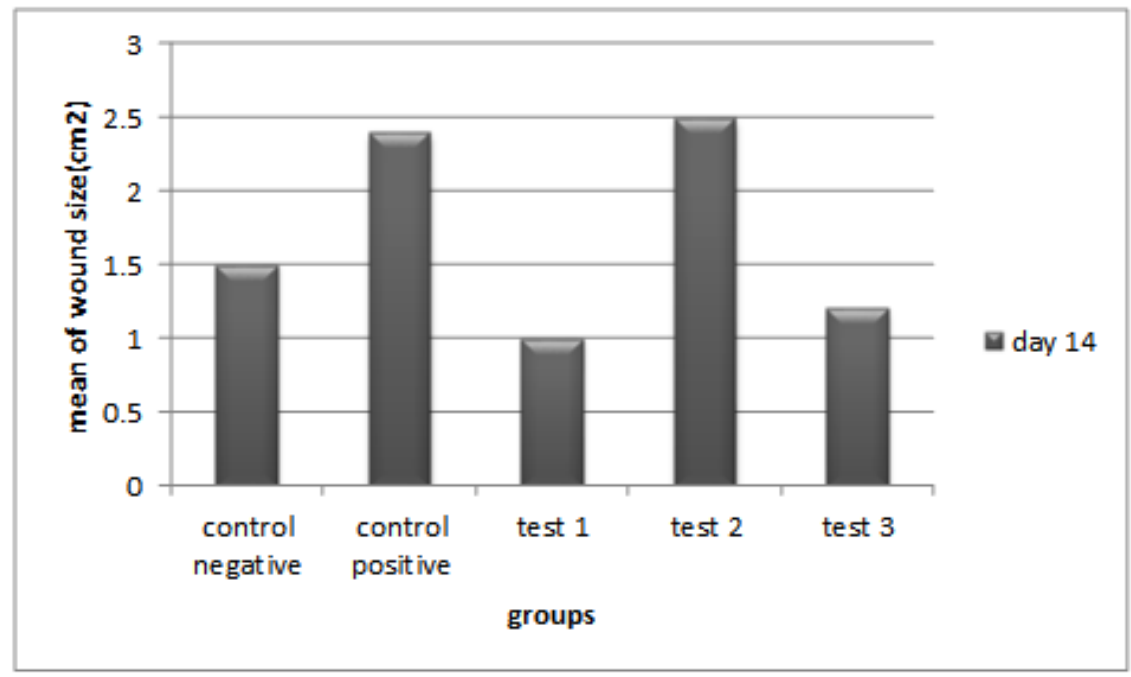

Fig. 3. Mean size of burn wounds in 5 groups $(\mathrm{n}=10$ each) on day 14 (post treatment).

Test 1, negative control: $(\mathrm{P}=0.001)^{*}$; test 1, positive control: $(\mathrm{P}=0.000)$; test 1 , test 2 : $(\mathrm{P}=0.03)$. Statistical method of ANOVA followed by Tukey as post Hoc test.

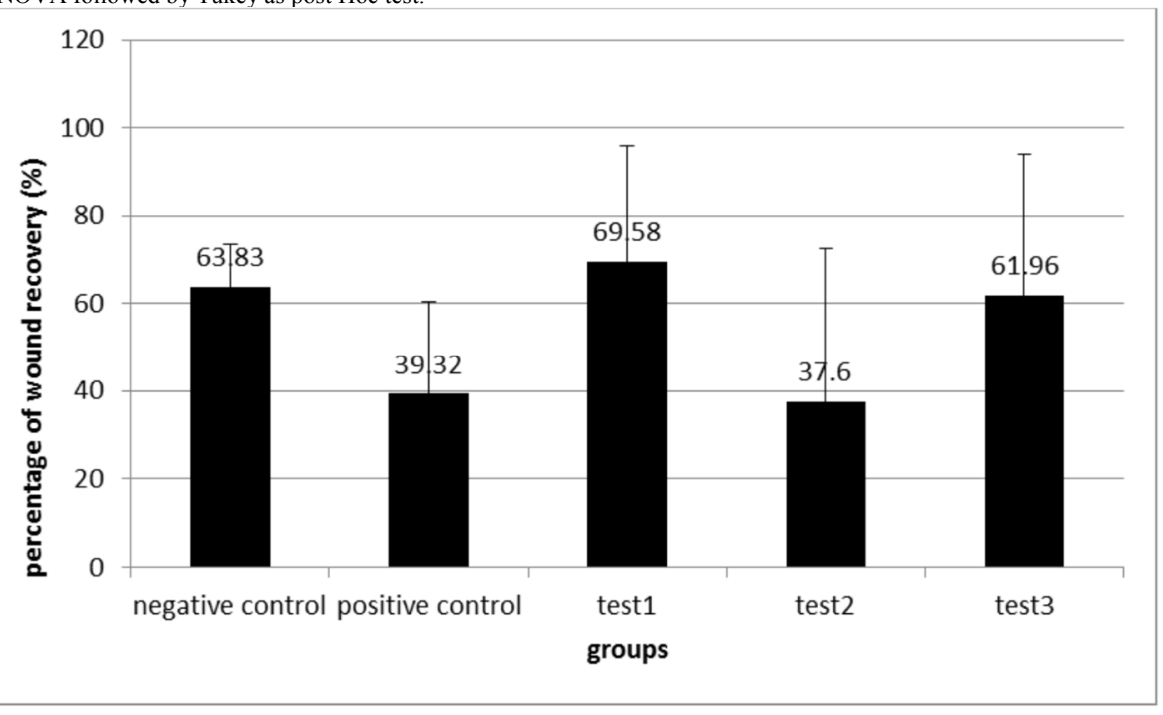

Fig. 4. The percentage of wound recovery after injury induction on the 14th day of treatment in 5 groups (mean \pm SD). The percentage of wound recovery surveyed by the statistical method of ANOVA (F; 3.16, df: 4, sig: $\left.0.022^{*}\right)$ followed by LSD as Post-Hoc test. Test 1, positive control: $(\mathrm{P}=0.014)^{*}$; test 1 , test $2:(\mathrm{P}=0.01)^{*}$; test 3 , test $2(\mathrm{P}=0.04) *$; negative control, positive control: $(\mathrm{P}=0.04)$ *

Groups: negative control; without treatment, positive control ; antibiotic, Test 1; probiotic cell pellet, Test 2; supernatant of probiotic, Test 3; probiotic cell pellet + supernatant of probiotic 
Control: treatment by eucerin ointment $+\mathrm{NaCl}$. Positive control: treatment by eucerin ointment + imipenem antibiotic. Test-1: treatment by eucerin ointment + probiotic cell pellet. Test-2: treatment by eucerin ointment + supernatant of probiotics. Test-3: treatment by eucerin ointment + probiotic cell pellet + supernatant of probiotics.

The mean size of the wounds in the test- 1 group was significantly lower than the negative and positive control groups on day 14 after the treatment; P-values were 0.001 and $<0.001$, respectively. Also, the results showed that on the same day, the mean size of the wounds in the probiotic cell pellet group was significantly lower than the supernatant group $(\mathrm{P}=0.003)$.

Then, the percentage of wound recovery was computed by comparison of the status of the wound on the first and the last day (Fig. 4). The percentage of wound recovery was calculated by ANOVA $(\mathrm{P}=0.022)$ followed by LSD and Post-Hoc test, and the results were compared in all groups.

According to Figure 4, the results showed that the percentage of wound recovery in test-1 group was higher than the positive control $(\mathrm{P}=0.014)$ and test- 2 groups $(\mathrm{P}=0.001)$ compared to others. This percentage in test-3 group was higher than the test- 2 group $(\mathrm{P}=0.004)$. The percentage of wound recovery in negative control was higher than the positive control group $(\mathrm{P}=0.004)$.

Hematological assessment of the burn wounds: The number of leukocytes was counted $24 \mathrm{~h}$ after the induction of burn and also on the $7^{\text {th }}$ and $14^{\text {th }}$ day of the treatment.
The mean leukocyte count for each group are demonstrated in Figure 5.

The mean number of white blood cells (WBCs) for the test groups 1, 2 and 3 were compared to the control groups on days 0,7 , and 14 . Results indicated that there was a significant increase in the mean number of WBCs for test1 group, which was higher than the mean of the positive control group on day $14(\mathrm{P}=0.002)$. In addition, the number of WBCs was significantly higher in the test-2 group compared to the positive control group on day 14 $(\mathrm{P}=0.001)$ (Fig. 5).

Wound culture: Burn wounds of all animals were sampled to be checked for the possible presence of $P$. aeruginosa, the results of which are presented in Table 3.

The number of samples which were negative for $P$. aeruginosa growth was calculated for each rat separately on the last day of the treatment (total population of animals $=50$ ). On day $14, P$. aeruginosa was completely eliminated in all the test groups except for the positive control group. In the test- 3 group, $P$. aeruginosa growth was not observed on day 7 in addition to day 14 of treatment.

The results showed that the percentage of cases with no $P$. aeruginosa growth the percentage of the absence of pathogen growth have significant differences among the other comparison groups (Table 3). The number of cases with no P. aeruginosa growth on days 7 and 14 was calculated by $\chi^{2}$ statistical method, and the results were Chi-square $=29.20$, and Chi-square $=28.69(\mathrm{P}<0.001)$.

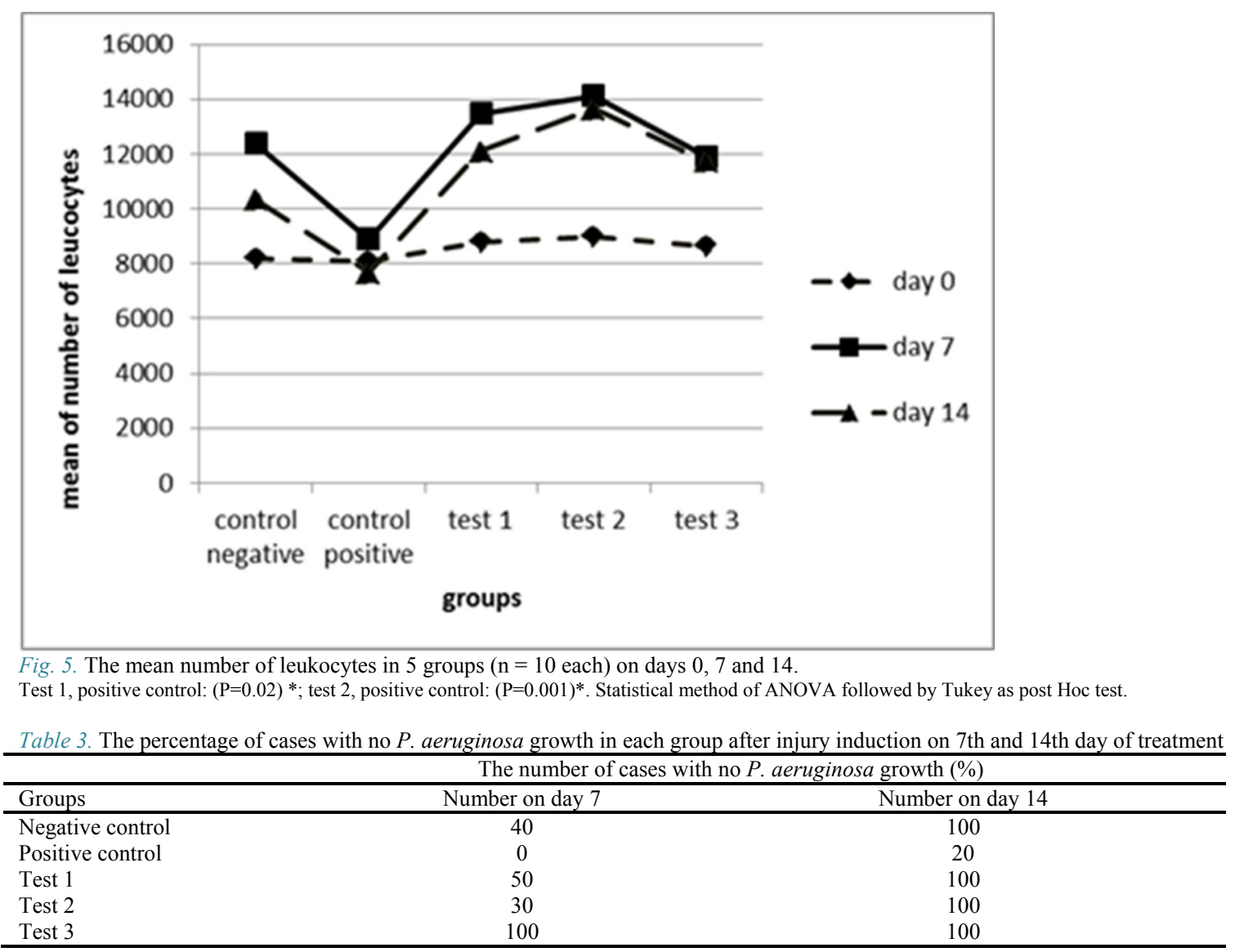




\section{Discussion}

Pseudomonas aeruginosa is an important cause of burn wound infections and because it is resistant to many antibiotics, making this microorganism a serious therapeutic problem (35-37). In several previous studies, $P$. aeruginosa isolates exhibited full or intermediate resistance to antimicrobial agents (38-41).

In addition, Pseudomonas spp. develop resistance to new antimicrobial agents faster than other gram-negative bacteria (42); therefore, in this study, P. aeruginosa was used to infect the burn wounds.

All of $P$. aeruginosa strains in our research were resistant to imipenem, cefepime, ciprofloxacin, ceftazidime. In our study, the microbial growth inhibitory activities of six potent probiotic strains were evaluated against $P$. aeruginosa. Among them, L. plantarum $299 \mathrm{v}$ was selected based on the diameter of the inhibitory zone for further study. It has been reported that L. plantarum is more functional in eliminating infections because of secreting short-chain fatty acids (43), bacteriocins (20), and other by-products (42).

Probiotics are considered to be useful microorganisms that involved in the regulation of the host's inflammatory and immune responses. Therefore, L. plantarum $299 v$ may be helpful for the treatment of burn wound infections. (36, $44,45)$ In addition, Lactobacillus spp. helps phagocytes avoid apoptosis caused by pathogens $(46,47)$.

In this study, in order to evaluate the microbial growth inhibitory effects of probiotics against $P$. aeruginosa, burned-rat models were used. After the induction of burn and inoculation of $P$. aeruginosa, burn wounds were treated with three different types of treatment protocols, including probiotic cell pellet, probiotic supernatant, and a combination of probiotic pellet and supernatant. Then the results were compared with the control groups.

Reduction of the size of the wound and its recovery rate are symptoms of wound healing and were evaluated in this study. In this research, in the group treated with probiotic pellet, wound healing was significantly better than the control groups on day 14 of the treatment. Also, we found that wound healing was much more pronounced in the probiotic cell pellet recipient group in comparison with supernatant and antibiotic-treated groups.

Moreover, the percentage of wound recovery in this group was significantly higher than the antibiotic-treated and test-2 groups.

It seems that the supernatant contains antimicrobial and anti-inflammatory agents that are produced by the probiotic bacteria. It also seems that the advantage of probiotic pellet over supernatant is due to the presence of the whole cell. Given that the bacterial cell is present, these compounds are constantly produced. Also, probiotics can promote the strength of the immune system and reduce inflammation and accelerate the wound healing process following the agglomeration of lymphocytes, macrophages, and polymorphonuclear in the damaged area $(48,49)$. In addition, probiotics can increase the collagenesis, hyaluronic acid, and antioxidants, which aid in wound healing and immune responses. On the other hand, the production of organic acids, bacteriocins, hydrogen peroxide, and ethanol by probiotics can help in the reduction of inflammation and improve the wound healing process $(35,50,51)$.

In this study, we observed that the number of WBCs increased in test groups on day 7 and 14, in comparison with the antibiotic-treated group. However, this result was statistically significant in the probiotic pellet treated group.

Several studies have demonstrated that Lactobacillus strains promote the immune system's capacity by increasing the cells of the innate immune system, including macrophages and neutrophils, which in turn can be associated with early inflammation (52-54).

There are several reports of enhancement of humoral and cellular immune response resulting from the administration of Lactobacillus species in animals and humans $(55,56)$. Furthermore, Lactobacillus spp. has been shown to increase the T-cell lymphocyte population in mice. Some probiotics can stimulate a protective immune response by competing against microbial pathogens (57).

In this study, the percentage of cases in which $P$. aeruginosa had no growth was investigated for each group after induction of the injury on the 7th and 14th day of treatment. The results revealed that this percentage was significantly different from those in other comparison groups. In all three test groups containing the probiotic pellet or supernatant of probiotics or pellet with supernatant of probiotics, $P$. aeruginosa was completely eliminated in comparison to the positive control group on day 14 but the group with a combination of pellet and supernatant of probiotics was more effective in the growth inhibition of $P$. aeruginosa compared with two other test groups.

Furthermore, it seems that the metabolites of $L$. plantarum299v could suppress the growth of $P$. aeruginosa. Similarly, other studies have demonstrated that Lactobacilli are able to inhibit the growth of $P$. aeruginosa by different mechanisms, such as the production of bacteriocin $(26,36)$

In this research, in all groups of probiotic recipients, $P$. aeruginosa was seen less in the wound in comparison with the antibiotic-treated group. It was remarkable that the antibiotic recipient (imipenem) group was the only group that failed to inhibit the growth of $P$. aeruginosa on day 14 after treatment, while this antibiotic is commonly used in the process of treating burns nowadays. Therefore, this inappropriate use of antibiotics can lead to the prevalence of antibiotic resistance (7). However, further research is needed for this issue.

\section{Conclusion}

In general, L. plantarum can act as a bio-therapeutic microorganism and may be a good candidate to overcome the growing challenge of nosocomial infections, but the use of probiotics and its by-products in topical wound treatments requires further investigation. The results of this study indicate that L. plantarum and its by-products can be used as an alternative to antibiotics to treat ulcer infections caused by resistant bacteria. 


\section{Acknowledgments}

This work was supported by Iran University of Medical Sciences with grant number 1393.24557.

\section{Conflict of Interests}

The authors declare that they have no competing interests.

\section{References}

1. Baker SP. The injury fact book: Oxford University Press, USA; 1992.

2. Sadeghi-Bazargani H, Maghsoudi H, Soudmand-Niri M, Ranjbar F, Mashadi-Abdollahi H. Stress disorder and PTSD after burn injuries: a prospective study of predictors of PTSD at Sina Burn Center, Iran. Neuropsychiatr Dis Treat. 2011;7:425.

3. McKibben JB, Ekselius L, Girasek DC, Gould NF, Holzer III C, Rosenberg M, et al. Epidemiology of burn injuries II: psychiatric and behavioural perspectives. Int Rev Psychiatry. 2009;21(6):512-21.

4. Roham M, Momeni M, Saberi M, Kheirkhah R, Jafarian A, Rahbar H. Epidemiologic analysis of central vein catheter infection in burn patients. Iran j microbiol. 2017;9(5):271.

5. Pfaller MA, Jones RN, Marshall SA, Coffman SL, Hollis RJ, Edmond $\mathrm{MB}$, et al. Inducible amp $\mathrm{C} \beta$-lactamase producing gram-negative bacilli from blood stream infections: Frequency, antimicrobial susceptibility, and molecular epidemiology in a national surveillance program (SCOPE). Diagn Microbiol Infect Dis. 1997;28(4):211-9.

6. Andersson DI, Levin BR. The biological cost of antibiotic resistance. Curr Opin Microbiol. 1999;2(5):489-93.

7. Guilfoile P, Alcamo IE. Antibiotic-resistant bacteria: Infobase Publishing; 2007.

8. Church D, Elsayed S, Reid O, Winston B, Lindsay R. Burn wound infections. Clin microbiol rev. 2006;19(2):403-34.

9. Japoni A, Farshad S, Alborzi A. Pseudomonas aeruginosa: burn infection, treatment and antibacterial resistance. Iran Red Crescent Med J. 2009;2009(3):244-53.

10. Stover C, Pham X, Erwin A, Mizoguchi S, Warrener P, Hickey M, et al. Complete genome sequence of Pseudomonas aeruginosa PAO1, an opportunistic pathogen. Nature. 2000;406(6799):959-64.

11. Laupland KB, Parkins MD, Church DL, Gregson DB, Louie TJ, Conly JM, et al. Population-Based Epidemiological Study of Infections Caused by Carbapenem-Resistant Pseudomonas aeruginosa in the Calgary Health Region: Importance of Metallo- $\beta$-Lactamase (MBL)-Producing Strains. J Infect Dis. 2005;192(9):1606-12.

12. Fuller R. Probiotics in human medicine. Gut. 1991;32(4):439.

13. Bernet MF, Brassart D, Neeser JR, Servin A. Lactobacillus acidophilus LA 1 binds to cultured human intestinal cell lines and inhibits cell attachment and cell invasion by enterovirulent bacteria. Gut. 1994;35(4):483-9.

14. Tenover FC, Hughes JM. WHO Scientific Working Group on monitoring and management of bacterial resistance to antimicrobial agents. Emerg Infect Dis. 1995;1(1):37.

15. Hill C, Guarner F, Reid G, Gibson GR, Merenstein DJ, Pot B, et al. Expert consensus document: The International Scientific Association for Probiotics and Prebiotics consensus statement on the scope and appropriate use of the term probiotic. Nat rev Gastroenterol \& hepatol. 2014;11(8):506-14.

16. Klarin B, Johansson ML, Molin G, Larsson A, Jeppsson B. Adhesion of the probiotic bacterium Lactobacillus plantarum 299v onto the gut mucosa in critically ill patients: a randomised open trial. Crit Care. 2005;9(3):R285.

17. Mangell P, Lennernaes P, Wang M, Olsson C, AhrnÉ S, Molin G, et al. Adhesive capability of Lactobacillus plantarum $299 \mathrm{v}$ is important for preventing bacterial translocation in endotoxemic rats. Apmis. 2006;114(9):611-8.

18. Petrof EO, Claud EC, Sun J, Abramova T, Guo Y, Waypa TS, et al. Bacteria-free solution derived from Lactobacillus plantarum inhibits multiple NF-kappaB pathways and inhibits proteasome function. Inflamm bowel dis. 2009;15(10):1537-47.

19. von Mollendorff JW, Vaz-Velho M, Todorov SD. Boza, a traditional cereal-based fermented beverage: a rich source of probiotics and bacteriocin-producing Lactic Acid Bacteria. Functional Properties of Traditional Foods: Springer; 2016. p. 157-88.

20. da Silva Sabo S, Vitolo M, González JMD, de Souza Oliveira RP.
Overview of Lactobacillus plantarum as a promising bacteriocin producer among lactic acid bacteria. Food Res Int. 2014;64:527-36.

21. Moghadam SS, Khodaii Z, Zadeh SF, Ghooshchian M, Aghmiyuni ZF, Shabestari TM. Synergistic or antagonistic effects of probiotics and antibiotics-alone or in combination-on antimicrobial-resistant pseudomonas aeruginosa isolated from burn wounds. Clin Infect Dis. 2018;13(3).

22. Peng Q, Zeng X, Zhu J, Wang S, Liu X, Hou C, et al. Effects of dietary Lactobacillus plantarum B1 on growth performance, intestinal microbiota, and short chain fatty acid profiles in broiler chickens. Poult Sci. 2016;95(4):893-900.

23. Johansson M-L, Nobaek S, Berggren A, Nyman M, Björck I, Ahrne S, et al. Survival of Lactobacillus plantarum DSM 9843 (299v), and effect on the short-chain fatty acid content of faeces after ingestion of a rose-hip drink with fermented oats. Int J Food Microbiol. 1998;42(1):29-38

24. Ducrotté P, Sawant P, Jayanthi V. Clinical trial: Lactobacillus plantarum 299v (DSM 9843) improves symptoms of irritable bowel syndrome. World J Gastroenterol. 2012;18(30):4012.

25. Valdez J, Peral M, Rachid M, Santana M, Perdigon G. Interference of Lactobacillus plantarum with Pseudomonas aeruginosa in vitro and in infected burns: the potential use of probiotics in wound treatment. Clin Microbiol Infect. 2005;11:472-9.

26. Goudarzvand M, Rasouli Koohi S, Khodaii Z, Soleymanzadeh Moghadam S. Probiotics Lactobacillus plantarum and bifidobacterium B94: cognitive function in demyelinated model. Med J Islam Repub Iran. 2016;30:391

27. Flórez AB, Egervärn M, Danielsen M, Tosi L, Morelli L, Lindgren $\mathrm{S}$, et al. Susceptibility of Lactobacillus plantarum strains to six antibiotics and definition of new susceptibility-resistance cutoff values. Microb Drug Resist. 2006;12(4):252-6.

28. Jonkers D, Stockbrügger R. Probiotics and inflammatory bowel disease. J R Soc Med. 2003;96(4):167-71.

29. Perry JD, Laine L, Hughes S, Nicholson A, Galloway A, Gould FK. Recovery of antimicrobial-resistant Pseudomonas aeruginosa from sputa of cystic fibrosis patients by culture on selective media $\mathrm{J}$ Antimicrob Chemother. 2008;61(5):1057-61

30. Bujalance C, Moreno E, Jimenez-Valera M, Ruiz-Bravo A. A probiotic strain of Lactobacillus plantarum stimulates lymphocyte responses in immunologically intact and immunocompromised mice. Int J Food Microbiol. 2007;113(1):28-34.

31. Kiehlbauch JA, Hannett GE, Salfinger M, Archinal W, Monserrat C, Carlyn C. Use of the National Committee for Clinical Laboratory Standards guidelines for disk diffusion susceptibility testing in New York state laboratories. J clin microbiol. 2000;38(9):3341-8.

32. Saadatzadeh A, Fazeli MR, Jamalifar H, Dinarvand R. Probiotic properties of Lyophilized cell free extract of Lactobacillus casei. Jundishapur J Nat Pharm Prod. 2013;8(3):131.

33. Puertollano E, Puertollano M, Cruz-Chamorro L, De Cienfuegos G, Ruiz-Bravo A, De Pablo M. Effects of concentrated supernatants recovered from Lactobacillus plantarum on Escherichia coli growth and on the viability of a human promyelocytic cell line. $\mathrm{J}$ appli microbiol 2009;106(4):1194-203

34. Dodelet-Devillers A, Zullian C, Beaudry F, Gourdon J, Chevrette J, Hélie $\mathrm{P}$, et al. Physiological and pharmacokinetic effects of multilevel caging on Sprague Dawley rats under ketamine-xylazine anesthesia. Exp anim. 2016;65(4):383-92.

35. Huseini HF, Rahimzadeh G, Fazeli MR, Mehrazma M, Salehi M. Evaluation of wound healing activities of kefir products. Burns. 2012;38(5):719-23

36. Valdez J, Peral M, Rachid M, Santana M, Perdigon G. Interference of Lactobacillus plantarum with Pseudomonas aeruginosa in vitro and in infected burns: the potential use of probiotics in wound treatment Clin Microbiol Infect. 2005;11(6):472-9.

37. Nagoba B, Selkar S, Wadher B, Gandhi R. Acetic acid treatment of pseudomonal wound infections-a review. J Infect Public Health. 2013;6(6):410-5.

38. Slama TG. Gram-negative antibiotic resistance: there is a price to pay. Crit Care. 2008;12(4):S4.

39. Chopra I, Schofield C, Everett M, O'Neill A, Miller K, Wilcox M, et al. Treatment of health-care-associated infections caused by Gramnegative bacteria: a consensus statement. Lancet Infect Dis. 2008;8(2):133-9

40. Nicasio AM, Kuti JL, Nicolau DP. The current state of multidrugresistant gram-negative bacilli in North America. Pharmacotherapy. 
2008;28(2):235-49.

41. Siegel RE. Emerging gram-negative antibiotic resistance: daunting challenges, declining sensitivities, and dire consequences. Respir care. 2008;53(4):471-9.

42. Aksungar FB, Topkaya AE, Akyildiz M. Interleukin-6, C-reactive protein and biochemical parameters during prolonged intermittent fasting. Ann Nutr Metab. 2007;51(1):88-95.

43. Wullt M, Hagslätt M-LJ, Odenholt I, Berggren A. Lactobacillus plantarum 299v enhances the concentrations of fecal short-chain fatty acids in patients with recurrent Clostridium difficile-associated diarrhea. Dig Dis Sci. 2007;52(9):2082.

44. Hardy H, Harris J, Lyon E, Beal J, Foey AD. Probiotics, prebiotics and immunomodulation of gut mucosal defences: homeostasis and immunopathology. Nutrients. 2013;5(6):1869-912.

45. Peral MC, Huaman Martinez MA, Valdez JC. Bacteriotherapy with Lactobacillus plantarum in burns. Int Wound J. 2009;6(1):73-81.

46. Dacheux D, Toussaint B, Richard M, Brochier G, Croize J, Attree I. Pseudomonas aeruginosa cystic fibrosis isolates induce rapid, type III secretion-dependent, but ExoU-independent, oncosis of macrophages and polymorphonuclear neutrophils. Infect Immun. 2000;68(5):291624.

47. Carlos Valdez J, Rachid M, Gobbato N, Perdigon G. Lactic acid bacteria induce apoptosis inhibition in Salmonella typhimurium infected macrophages. Food agric immunol. 2001;13(3):189-97.

48. Witthuhn R, Schoeman T, Britz T. Characterisation of the microbial population at different stages of Kefir production and Kefir grain mass cultivation. Int Dairy J. 2005;15(4):383-9.

49. Huseini HF, Rahimzadeh G, Fazeli MR, Mehrazma M, Salehi M. Evaluation of wound healing activities of kefir products. Burns. 2012;38(5):719-23.

50. Atalan G, Demirkan I, Yaman H, Cina M. Effect of topical kefir application on open wound healing on in vivo study. Kafkas Uni Vet Fak Derg. 2003;9(1):43-7.

51. Witthuhn R, Schoeman T, Cilliers A, Britz T. Impact of preservation and different packaging conditions on the microbial community and activity of Kefir grains. Food Microbiol. 2005;22(4):337-44.

52. Rocha-Ramírez L, Pérez-Solano R, Castañón-Alonso S, Moreno Guerrero S, Ramírez Pacheco A, García Garibay M, et al. Probiotic Lactobacillus Strains Stimulate the Inflammatory Response and Activate Human Macrophages. J Immunol Res. 2017;2017.

53. Perdigón G, Fuller R, Raya R. Lactic acid bacteria and their effect on the immune system. Curr Issues Intest Microbiol. 2001;2(1):27-42.

54. Kato I, Yokokura T, Mutai M. Macrophage activation by Lactobacillus casei in mice. Microbiol Immunol. 1983;27(7):611-8.

55. Wells JM. Immunomodulatory mechanisms of lactobacilli. Microb cell factori. 2011;10(1):S17.

56. Haghighi HR, Gong J, Gyles CL, Hayes MA, Sanei B, Parvizi P, et al. Modulation of Antibody-Mediated Immune Response by Probiotics in Chickens. Clin Diagn Lab Immunol. 2005;12(12):138792.

57. Koenen M, Kramer J, van der Hülst R, Heres L, Jeurissen S, Boersma W. Immunomodulatory effects of multistrain probiotics (Protexin ${ }^{\mathrm{TM}}$ ) on broiler chicken vaccinated against Avian Influenza Virus (H9). Br Poult Sci. 2004;45:355-66. 